\title{
Teacher Candidates Perceptions of a Course Assignment Designed to Support a Teacher Performance Assessment
}

\author{
Carmen Sherry Brown ${ }^{1}$ \\ ${ }^{1}$ Department of Curriculum and Teaching, Hunter College, City University of New York (CUNY), USA \\ Correspondence: Carmen Sherry Brown, Department of Curriculum and Teaching, Hunter College, City \\ University of New York (CUNY), USA. E-mail: cb95@ hunter.cuny.edu
}

Received: February 3, 2018

Accepted: February 20, $2018 \quad$ Online Published: April 10, 2018

doi:10.5539/hes.v8n2p58

URL: https://doi.org/10.5539/hes.v8n2p58

\begin{abstract}
To guide and support teacher candidates in developing the knowledge and skills they need in the classroom, teacher preparation programs must prepare students in acquiring the experience and expertise needed to demonstrate mastery of general knowledge in the specific subject or content area. In addition, teacher preparation programs must support candidates in maintaining knowledge of professional preparation and education competence that will guide student development. Therefore, faculty in teacher preparation programs are critical in supporting pre-service teachers in acquiring and developing the knowledge and skills in order to be effective and efficient in the classroom and to meet licensure requirements. To support the alignment of early childhood coursework in a teacher preparation program with a Teacher Performance Assessment (edTPA), the purpose of this study was to determine the efficacy of a redesigned course assignment that was intended to support the edTPA. The findings indicated that there are opportunities for candidates to develop their practice through course assignments that are aligned with the language and expectations of the edTPA.
\end{abstract}

Keywords: pre-service teachers, teacher preparation, teacher licensure

\section{Introduction}

According to the National Council for Accreditation of Teacher Education (NCATE, 2012), two components are critically important in teacher preparation: teacher knowledge of the subject to be taught and knowledge and skill in how to teach that subject (p.4). With the requirements and accountability of becoming certified to teach in New York State (NYS) becoming more rigorous and demanding, there is a renewed effort to better prepare teacher candidates and aligning coursework to support them in meeting these requirements. While teacher candidates are expected to demonstrate a meaningful level of content and pedagogical knowledge through coursework and teacher certification exams, they are also expected to submit and pass a portfolio-based teacher performance assessment (edTPA) before earning initial teacher certification in NYS.

Even though the teacher certification exams have been in place in various formats prior to 2014, the edTPA is a new requirement in NYS beginning in May 2014. The edTPA consists of 3 tasks (planning, teaching, and assessment) that teacher candidates must complete to measure their readiness to teach. Each task consists of evidence of teacher candidates' work in that area as well as a series of questions guiding student teachers to reflect on their practice.

To guide and support teacher candidates in developing the knowledge and skills they need in the classroom, teacher preparation programs must prepare students in acquiring the experience and expertise needed to demonstrate mastery of general knowledge in the specific subject or content area. In addition, teacher preparation programs must support candidates in maintaining knowledge of professional preparation and education competence that will guide student development. Therefore, faculty in teacher preparation programs are critical in supporting pre-service teachers in acquiring and developing the knowledge, skills and values in order to be effective and efficient in the classroom.

\section{Perspectives}

\subsection{High Quality Teacher Preparation}

Research is clear that effective early childhood teaching is highly skilled work that requires specific knowledge, skills and mastery of a body of practical techniques (Ryan \& Gibson, 2016; Whitebook, 2014). However, studies 
have found that the majority of professionals who make up the current early childhood workforce are not adequately prepared (Demma \& LeMoine, 2010; Herzenberg, Price \& Bradley, 2005; Rhodes \& Huston, 2012). The National Association for the Education of Young Children (NAEYC) states that "all early childhood professionals should have a broad knowledge of development and learning across the birth-through-age- 8 range; should be familiar with appropriate curriculum and assessment approaches across that age span; and should have in-depth knowledge and skills in at least two of the three periods: infants/toddlers, preschool/ prekindergarten, and early primary grades" (NAEYC, 2009, p. 4).

High quality early childhood teacher preparation and pre-service professional development support teacher candidates in developing specialized knowledge, skills, and practices that support the educational achievement of young children (NAEYC, 2011). What early childhood teachers know and are able to do is one of the major influences on the learning and development of young children. Early childhood teachers need a wide range of skills, knowledge and experience to support and guide young children in achieving high outcomes. Within teacher preparation programs, methods courses designed to influence practice have been shown to be effective (Osisioma \& Moscovici, 2008). In order to prepare teacher candidates to work with children from birth to age 8 , coursework in early childhood teacher preparation programs must provide them with the knowledge of the early learning process, child development, and academic content while supporting them in submitting and passing the required exams to become certified to teach.

\section{2 edTPA-Early Childhood}

The purpose of the edTPA-Early Childhood is to measure teacher candidates' readiness to teach young children, ages 3-8. The assessment is designed with a focus on children's learning and principles from research and theory. It is based on findings that successful teachers:

1. Develop knowledge of subject matter, content standards, and subject-specific pedagogy.

2. Develop and apply knowledge of varied children's needs.

3. Consider research and theory about how children learn reflect on and analyze evidence of the effects of instruction on children's learning (SCALE, 2015, p.1).

The edTPA-Early Childhood assessment is comprised of three tasks: Task 1: Planning for instruction and assessment; Task 2: Instructing and engaging children in learning and, Task 3: Assessing children's learning. The three edTPA tasks represent a cycle of effective teaching: Task 1 documents the teacher candidates' intended teaching; Task 2 documents the enacted teaching; and Task 3 documents the impact of the teaching on student learning (SCALE, 2015). The edTPA is designed to engage teacher candidates in demonstrating their understanding of teaching and children's learning in authentic ways (SCALE, 2015, p.1).

\section{Purpose of the Study}

To support the alignment of early childhood coursework in a teacher preparation program with the edTPA, the purpose of this study was to determine the efficacy of a redesigned course assignment that was intended to support the teacher performance assessment. The objectives of the study were to analyze teacher candidates' perceptions of the assignment with regards to supporting the demands and expectations of the edTPA. In addition, this study also sought to determine the strengths of the assignment and identify areas that needed further development in order to support the specific requirements of the edTPA. To determine the efficacy of the course assignment the following research questions was posited:

1. How did the early childhood teacher candidates perceive the efficacy of the assignment in preparing them for the edTPA tasks and components?

2. What were the strengths of the assignment as perceived by the teacher candidates?

3. What areas needed further development as perceived by the teacher candidates?

\section{Assignment and Courses}

In the spring 2014 semester, a video analysis and reflection assignment was created within 2 method courses in an early childhood program that led to a Master of Science degree. The new requirement was embedded into an existing assignment within a language and literacy and early mathematics course. The assignment was designed to support teacher candidates in aligning, modeling, and employing pedagogical approaches that bridge theory and practice, guides assessment of young children and prompt teacher candidates' reflection. The existing assignment required the teacher candidates to plan developmentally appropriate activities and document the developmental progression of a case study over the course of a 15-week semester. The new assignment required the teacher candidates to video record one of their activities, assess the effectiveness of their teaching and reflect upon their instructional support. The teacher candidates were given guidelines and prompts to support their analysis. 


\subsection{Early Language and Literacy}

This course examines the process of early literacy development from birth through kindergarten. Research and practice in language learning and the development of early literacy skills among diverse learners are also explored. Teacher candidates supplement their readings and study with actual observations and reporting of children's language and literacy behaviors, collaborate to assess and develop supportive classroom environments and create theme-based literacy plans. The final assignment for the course, Oral and Written Language Development Case Study, requires students to choose one child (3 months-5 years), obtain relevant background information, collect reading, writing, and language samples from the child over a 3-month period and create a portfolio of observations, assessments, work and language samples. Based on the analysis of the portfolio items, teacher candidates describe 4-6 activities that will support the child's continued oral and written language development.

\subsection{Early Childhood Mathematics}

This course examines the educational and psychological research and theories concerning the development of children's (birth-Grade 2) mathematical thinking. It considers applications of this knowledge to teaching and assessment in the early childhood classroom. Teacher candidates are engaged in developing and implementing appropriate activities and materials that promote children's mathematical understanding as well as assessing children's mathematical learning. For the final assignment, Math Implementation and Impact Project, teacher candidates develop and implement appropriate math activities for young children. To support teacher candidates in understanding how and what children learn from the activities, they assess children's learning through observations and clinical interviews. They are also required to provide an evaluation of children's learning and understanding of mathematics based on their observations of children during and after the implemented activities as well as using their clinical interview and anecdotal recordings. The goal of this assignment is to provide teacher candidates with an opportunity to use their individual creativity to develop math activities as well as to draw upon and synthesize much of what they learned in the course.

\section{Methods}

\subsection{Participants}

The participants were teacher candidates who attended a public college located in a large urban area. Teacher candidates who took one or both of the redesigned method courses in the Fall (2014) and Spring (2015) semesters and had submitted their edTPA portfolios were recruited to participate in this study. Students who had taken one or both of the redesigned courses in the Fall (2015) semester and were preparing their edTPA portfolios for submission were also recruited to participate in the study. A total of 18 early childhood teacher candidates participated in this study.

\subsection{Questionnaire}

To determine teacher candidates perceptions of the assignment with regards to supporting the demands and expectations of the edTPA and to identify the strengths and areas that need further development in supporting specific aspects of the tasks in the teacher performance assessment, a questionnaire was developed (Appendix A). The questionnaire was designed to ascertain teacher candidate's familiarity, preparation and support as well as an overall measure of the attitudes and opinions of the teacher candidates with regards to the expectations of the edTPA. To increase the likelihood that responses reflected genuinely held opinions, the questionnaires were anonymous.

\subsection{Focus Group}

In order to gain more insight about the teacher candidates' perceptions regarding the assignment as well as draw upon their experiences and reactions, data was collected through a semi-structured group interview that was audio recorded. The interview participants were asked a series of thematic, predetermined questions regarding the efficacy of the course assignment. The predetermined questions provided more focus than the conversational approach, but still allowed a degree of freedom and adaptability in acquiring authentic information from the participants. Ten early childhood teacher candidates participated in two focus groups.

\subsection{Phone Interview}

The remaining 8 teacher candidates, who were unavailable for the focus group, participated in a one-on-one phone interview. To ensure that the same general areas of information were collected as the focus group interviews, the phone interview participants were asked the same series of thematic questions regarding the efficacy of the course assignment. 


\subsection{Data Analysis}

In order to describe and quantify the specific areas of inquiry related to the efficacy of the course assignment and to provide a systematic and objective means to make valid inferences from the data, content analysis was used to analyze the focus group and phone interviews. The goal of content analysis is to provide knowledge and understanding of the phenomenon under study. Hsieh and Shannon (2005) define qualitative content analysis as a "research method for the subjective interpretation of the content of text data through the systematic classification process of coding and identifying themes or patterns" (p.1278).

The audio recording of the interviews were transcribed and, using conventional content analysis, the coding categories were derived directly from the text data. Coding also allowed for synthesizing and summarizing the data and aligning it with the questionnaire responses. The questionnaire items were analyzed to identify specific elements of the assignment that were practical in supporting the demands of the edTPA. Each section of the questionnaire, expectations, familiarity, and preparation, was analyzed in alignment with the edTPA tasks and components to determine the identified areas that the teacher candidates reported as supporting them with the edTPA. To differentiate between the two courses and to optimize the information obtained from the questionnaire, the answers for the specific courses were analyzed separately. In addition, where applicable, the elements that teacher candidates indicated were not helpful in preparing them for the edTPA were explored. Table 1 denotes a sample coding aligned with the edTPA and questionnaire.

Table 1. Sample coding

edTPA Task 1: Planning for Instruction and Assessment

$100 \%$ of the teacher candidates indicated that the courses provided support for the planning components of Task 1

"The courses and the assignment taught me that teachers are responsible for promoting each child's development by planning lessons and activities that are developmentally appropriate and based on the need of each student. I knew this was important for the edTPA and was prepared to write lesson plans that were meaningful for the children in my class"

"The class has shown me how to plan with an objective, which is not only about what I am going to accomplish, but also, how I am targeting children with different learning abilities and needs. In the past I really focused on my own successful execution of my lesson plan. Now I have learned that the focus must be on how well and how much the students have learned as a result of the lesson plan."

"With the class and the assignment I was truly able to prepare my lessons and research the theories and activities that will complement them."

"I was grateful for the structure of the lesson plan outline. Because I was familiar with it, I was able to focus on my objectives. It met the requirements of the edTPA. I did not have to look for one because the program provided us with one."

\section{Findings}

The findings indicated that there are opportunities for candidates to develop their practice through course assignments that are aligned with the language and expectations of the edTPA. One hundred percent of the teacher candidates indicated that they were somewhat or very familiar with the requirements of the edTPA tasks and that the video analysis and reflection assignment provided them with maximum or some support in preparation for the teacher performance assessment. Twenty five percent of the teacher candidates indicated that the assignment in the language and literacy course offered no support for some of the edTPA components such as reflection and documentation while 17\% stated that the mathematics course assignment provided no support for edTPA requirements such as collecting artifacts. While the teacher candidates confirmed that the assignments in both courses prepared them for the demands and expectations of the edTPA during the focus group and phone interviews, they made suggestions on how the assignments could be further developed to support future teacher candidates preparing for teacher performance assessments.

During analysis, the following themes emerged: Planning, oral language and vocabulary, and assessments. The following section discusses the themes and their alignment to the edTPA tasks.

\section{Themes}

\subsection{Planning}

EdTPA Task 1: Planning and assessment required the early childhood teacher candidates to develop 3-5 consecutive learning experiences that build on each other and are to be implemented over the course of one week 
(Stanford Center for Assessment, Learning, and Equity (SCALE), 2015). In early education settings, learning experiences provide young children with the skills and learning opportunities that are designed to support them in their development (NAEYC, 2009). Teacher candidates stated that the lesson plan template that was used for the assignment was beneficial and useful for planning learning experiences that aligned with the requirements of the teacher performance assessment. A teacher candidate said, "I want to mention that the preparation for the edTPA learning segments using the template helped me to think of the overall picture of instruction, assessment, follow up extension activities and differentiated instruction, among others. As I was using the template, areas that I didn't take into consideration came to clarity and along the process of planning the learning segment I was able to address them in a better way." Another teacher candidate stated, "I was grateful for the structure of the lesson plan outline. Because I was familiar with it, I was able to focus on my objectives...It met the requirements of the edTPA. I did not have to look for one because the program provided us with one."

\subsection{Oral Language and Vocabulary}

EdTPA Task 1: Planning and Assessment requires teacher candidates to state the central focus for their learning segment that will allow them to address children's language and literacy as well as identify the vocabulary children need to know and use to engage in the learning (SCALE, 2015). Oral language refers to all aspects of spoken language, including children's growing vocabularies of new and varied words (Hoffman \& Cassano, 2013). Oral language is often associated with vocabulary as the main component. The process of acquiring and using words in oral and written contexts is a life-long learning process that begins during the early years (Sinatra, Zygouris-Coe, \& Dasinger, 2011). Early vocabulary acquisition is critical because of the relationship between vocabulary knowledge and reading comprehension (Fitzgerald \& Graves, 2005).

All of the teacher candidates indicated that they were very or somewhat familiar with the language and vocabulary development edTPA evaluation criteria. They also stated that the math course video analysis and reflection assignment provided maximum or some support for this edTPA requirement while some of the teacher candidates stated that the language and literacy course provided no support for this requirement.

During analysis, there was a misalignment between the answers indicated on the questionnaire and the responses provided during the focus group and telephone interviews in how the video analysis and reflection assignment supported the language and vocabulary edTPA requirement. Throughout both the focus group and phone interviews, teacher candidates indicated that the language and literacy course assignment provided guidance with regards to incorporating oral language and vocabulary during instructional activities. A teacher candidate said, "The components of early [literacy] development and the 3 tiers of vocabulary guided me in purposefully putting vocabulary in my lesson plans...I was really looking to support children and how they used the words when we were working together." There was no evidence during either the focus group or phone interviews that the language and literacy course assignment offered no support for the edTPA language and vocabulary requirement as some of the teacher candidates indicated on the questionnaire.

Even though all of the teacher candidates indicated that the video analysis and reflection assignment in the early childhood math course supported them with the language development requirement in the edTPA, during both the focus group and phone interviews they indicated that the course assignment could have put more emphasis on vocabulary and language facilitation in order to meet the requirements defined in the edTPA. A teacher candidate stated: "...the class could have put more intentionality and focus on the vocabulary needed to work with children on math activities...how to engage children in using the vocabulary during lessons would have been helpful." Another teacher candidate stated: "...there was so much attention on [math] development and appropriate activities...less attention on language and getting children to use language during activities." This indicated that the teacher candidates understood the importance of implementing developmentally appropriate math activities, but felt the course did not support or guide them with language or vocabulary development.

During data analysis, I was unable to discern why the teacher candidates indicated that the math course video analysis and reflection assignment support for the language development expectations defined in the edTPA in the questionnaire, but did not corroborate this during the interviews. The teacher candidates consistently stated that "math vocabulary" and "language development" could have been more emphasized as important for the edTPA not only in this specific assignment, but also in all of the required assignments in the math course. A teacher candidate said, "...labels in the environment help children with environmental print, but what about making a math rich environment with numbers and manipulatives representing math problems throughout the classroom."

Teacher candidates appeared to recognize the importance and validity of incorporating vocabulary and language development while implementing math activities. Many of them shared the viewpoint of Andrew Tyminski who 
stated that, "Vocabulary terms should be introduced to students through active engagement in mathematics where possible and that students should be allowed and encouraged to find ways to describe the phenomenon they are interacting with in their own words." (Dunston \& Tyminski, 2013, p.39)

\subsection{Assessment}

Early childhood assessment is a process of gathering information about a child, reviewing the information, and then using the information to plan educational activities that are at a level the child can understand and is able to learn from (Snow \& Van Hemel, 2008). The assessment is a tool used to gather and provide educators and parents with critical information about a child's development and growth. EdTPA Task 3: Assessing Children's Learning requires teacher candidates to analyze children's learning and their use of key vocabulary as well as identifying quantitative and qualitative patterns of learning. The edTPA-Early Childhood encourages teacher candidates to discuss how they will analyze the evidence of children's learning and vocabulary use, how they will provide meaningful feedback to the children, and how they will use evidence of what children know and are able to do to plan next steps in instruction (SCALE, 2015, p. 29). All of the teacher candidates indicated that they were very or somewhat familiar with the assessment edTPA evaluation criteria and that the video analysis and reflection assignment in both the language and literacy and math courses provided support for this edTPA requirement.

Even though teacher candidates indicated that the assignment in both courses provided support for edTPA Task 3, $72 \%$ of the teacher candidates indicated that they needed maximum or some support during the completion of their portfolios. During the focus group and telephone interviews, teacher candidates consistently stated that this was the edTPA component that they needed the most guidance and practice with. A teacher candidate stated, "I had a hard time identifying the evidence needed for the assessment. The [other] courses did not give us a lot of practice looking at assessment or activities with the case study project. I could have used more guidance and support with this." This indicated that the teacher candidates appeared to be aware of the specific edTPA component they needed additional support with.

Teacher candidates also indicated that the lesson plan template provided a guideline for developing activities, but was not very clear on how to assess children even though there was an area for documenting assessment. The lesson plan template has a designated area where teacher candidates document their method of assessing children's understanding of the lesson objective(s), the pre-assessment used to determine their prior knowledge as well as the assessment of student learning and how they will assess language learning. A teacher candidate stated, "...I would have benefitted from more discussion on assessing of student learning and language development...and the main difference...this was confusing." Teacher candidates clearly stated that more examples and guidance for completing this area of the lesson plan template would have been beneficial while completing edTPA Task 3, “...I felt frustrated because I did not know how to explain [assessment] in writing...I knew the objectives and rationale of assessing...this is where I did poorly."

\section{Recommendations}

In designing courses, assignments and clinical experiences that support teacher candidates, research-based principles should be applied that are aligned with the cycle of effective teaching that is identified in the edTPA. The cyclical relationship among planning, instruction, and assessment, with a focus on children's learning needs, should be emphasized throughout the course of study in an early childhood teacher preparation program. The results of this inquiry led to the following recommendations for the early childhood program.

\subsection{Recommendation \#1: More Experience Writing Learning Segments}

While all of the teacher candidates indicated that they were very or somewhat familiar with lesson planning, they stated that they would have benefitted from writing more lesson plans during their course of study. During the focus group interviews, there was a strong consensus amongst the teacher candidates that lesson planning, writing learning segments and the use of the template should be incorporated more into other coursework in the early childhood education program.

\subsubsection{Implications}

Creating an effective learning segment takes time, attention to detail and diligence. It must include an explicit sequence that incorporates an understanding of children's development. An effective learning segment addresses and integrates objectives for student learning, teaching and instruction. It must also incorporate strategies to assess student understanding and acquisition of knowledge and differentiated strategies to support children who need additional guidance or extra challenges. Teacher candidates should have multiple opportunities during their course of study and clinical experiences to create learning segments and use lesson plan templates. The lesson 
plan template must be consistent across courses and should include the learning objectives, the resources needed to support them, the instructional activities that guide the objectives and the assessment method used to determine if the objectives are being met for learning and teaching.

\subsection{Recommendation \#2: Vocabulary in the Content Area}

The content disciplines can be an abundant source for vocabulary development, but vocabulary instruction is often isolated from content area learning (Fisher \& Frey, 2014). Teacher candidates indicated that more support and guidance for vocabulary and language instruction should be embedded into the early mathematics course to support the demands of the edTPA.

\subsubsection{Implications}

Vocabulary learning is a continual process of encountering new words in meaningful and comprehensible contexts (Harmon, Wood, Hedrick, \& Gress, 2008). Vocabulary knowledge provides young learners with a foundation they can apply and build upon in and out of the classroom. The content disciplines can be an abundant source for vocabulary development, but vocabulary instruction is often isolated from content area learning (Fisher \& Frey, 2014). When creating lessons plans and learning segments, teachers should keep four factors in mind when they consider strategies to teach vocabulary:

1. The students they are teaching.

2. The nature of the words they decide to teach.

3. Their instructional purposes in teaching each of those words.

4. The strategies they employ to teach the words (Flanigan \& Greenwood, 2007).

When teacher candidates are observed during student teaching demonstrations, field supervisors should document how the candidates model an attitude of enthusiasm and excitement that will encourage an interest in words and language by their students. For reflective purposes, they should document how the teacher candidates infuse vocabulary instruction and facilitate language development throughout the day.

As this inquiry analyzed an assignment embedded in an early childhood mathematics course, to support young children in assimilating and using vocabulary knowledge essential to learning mathematics, the following strategies are encouraged:

- Pre-teach mathematics vocabulary.

- Model vocabulary when teaching new concepts.

- Use appropriate labels clearly and consistently.

- Integrate vocabulary knowledge in assessments (Chard, n.d.).

In addition, to guide children whose need additional support with vocabulary development (e.g., ENL, developmental delays), visual cues, graphic representations, gestures, and pictures should be used. Allow young children the opportunity to work with manipulatives and objects in order to have exposure and experiences with the associated vocabulary.

\subsection{Recommendation \#3: Assessments}

Early childhood assessment is the process of observing, recording, and documenting the work children do and how they do it (Koralek, Dodge, \& Pizzolongo, 2008). Ongoing assessment is essential as it allows teachers and caregivers to gather information about young children in order to plan instructional activities that meet their individual needs. It also helps in identifying if and how children are making progress toward identified goals. When used appropriately, assessments can support and guide student learning as well as enhance teaching.

Early childhood teacher preparation faculty should model appropriate uses of assessment to enhance learning by demonstrating that assessments should bring about benefits for all children, should be age and linguistically appropriate in both content and the method of data collection, and recognize that parents are a valuable source of assessment information. When reviewing and reflecting upon an observed lesson, field supervisors should ensure that teacher candidates understand the importance of incorporating how they will observe and collect data in their lesson plans. Field supervisors and program faculty must also support teacher candidates in understanding how to utilize the assessment data to inform curriculum decisions and set appropriate goals to support children's development.

\subsubsection{Implications}

Early childhood teacher preparation faculty should model appropriate uses of assessment to enhance learning by demonstrating that assessments should bring about benefits for all children, should be age and linguistically appropriate in both content and the method of data collection, and recognize that parents are a valuable source of 
assessment information.

To complete the edTPA, teacher candidates apply what they have learned from their coursework in early childhood preparation programs as well as field and student teaching experiences by documenting teaching and assessment of learning during a learning segment and providing commentary explaining, analyzing, and reflecting on their instruction, teaching and children's learning. Early childhood professional preparation programs should have a strong foundation in the areas of child development, curriculum, assessment, diversity, inclusion, and family relations as recommended by NAEYC that support this premise.

\section{Limitations}

This inquiry was intentionally focused on improving identified courses and supporting teacher candidates in a specific program with a teacher performance assessment and can not be generalized to other teacher preparation programs. While much of the research on improving early childhood educators' skills and knowledge has focused on in-service professional development rather than pre-service training (Zaslow, Tout, Halle, Whittaker $\&$ Lavelle, 2010), this research can support higher education early childhood programs in improving pre-service training program quality and aligning the content of courses, coursework and field experiences with the language and expectation of teacher performance assessments.

\section{Conclusion}

The edTPA was designed as a comprehensive portfolio to depict teacher candidates' readiness to teach as part of the teacher licensure process. Teacher preparation programs must exercise extreme caution while preparing teacher candidates for the practicalities of the field and licensure and not be inclined to teach to the test. This inquiry evaluated the efficacy of a methods course assignment, which was embedded in an existing project, to support the requirements of the edTPA. While the assignment was intended to support the expectations of the edTPA, the overall course was intended to give teacher candidates in-depth knowledge and experience in identified content.

Today's teachers will have to educate all students, including those from increasingly diverse economic, racial, linguistic, and academic backgrounds. Teacher preparation programs must provide teacher candidates with multiple opportunities, throughout their coursework and various field experiences, to gain the critical knowledge, skills and dispositions needed to teach all children. Although the analysis from this inquiry indicated that the early childhood teacher candidates perceived the efficacy of the video analysis and reflection assignment in both the mathematics and language and literacy courses as valuable in preparing them for the edTPA, there is little research looking at the specific practices of early childhood preparation programs and teacher candidates perception about their efficacy in preparing them for certification exams, teacher performance assessments and preparation for authentic classroom experiences that include diverse students. While the suggestions the teacher candidates made will support future early childhood teacher candidates as they prepare for certification, subsequent research should further examine the relationship between specific program preparation practices and outcomes such as the quality of classroom practices and student learning gains in diverse settings.

\section{References}

Chard, D. (n.d.). Vocabulary strategies for the mathematics classroom. Houghton Mifflin. Retrieved March 26, 2010 from: https://www.eduplace.com/state/pdf/author/chard_hmm05.pdf

Demma, R., \& LeMoine, S. (2010). Building an early childhood professional development system. Issue Brief. Washington, DC: National Governors Association Center for Best Practices. Retrieved April 9, 2015 from: https://www.nga.org/files/live/sites/NGA/files/pdf/1002EARLYCHILDPROFDEV.PDF

Dunston, P. J., \& Tyminski, A. M. (2013). What's the big deal about vocabulary? Mathematics Teaching in the Middle School, 19(1), 38-45. https://doi.org/10.5951/mathteacmiddscho.19.1.0038

Fitzgerald, J., \& Graves, M. F. (2005). Reading supports for all. Educational Leadership, 62 (4), 68-71. Retrieved on January 20, 2015 from: http://www.ascd.org/publications/educational-leadership/dec04/vol62/num04/Reading-Supports-for-All.aspx

Fisher, D., \& Frey, N. (2014). Content area vocabulary learning. The Reading Teacher, 67(8), 594-599. https://doi.org/10.1002/trtr.1258

Harmon, J. M., Wood, K. D., Hedrick, W. B., \& Gress, M. (2008). Pick a word-not just any word: Using vocabulary self-selection with expository texts. Middle School Journal, 40(1), 43-52. https://doi.org/10.1080/00940771.2008.11461664

Herzenberg, S., Price, M., \& Bradley, D. (2005). Losing ground in early childhood education: Declining workforce 
qualifications in an expanding industry, 1979-2004: Summary. Washington, DC: Economic Policy Institute. Retrieved March 25, 2015 from: https://www.fcd-us.org/assets/2016/04/LosingGroundinEarlyChildhoodEducation.pdf

Hsieh, H. F., \& Shannon, S. E. (2005). Three approaches to qualitative content analysis. Qualitative health research, 15(9), 1277-1288. https://doi.org/10.1177/1049732305276687

Hoffman, J. L., \& Cassano, C. (2013). The beginning: Reading with babies and toddlers. In J. A. Schickedanz \& M. F. Collins (Eds.), So much more than ABC's: The early phases of reading and writing. Washington, DC: National Association for the Education of Young Children.

Koralek, D. G., Trister Dodge, D., \& Pizzolongo, P. (2008). Caring for Preschool Children, eCDA edition. Washington, DC: Teaching Strategies.

National Association for the Education of Young Children (NAEYC). (2009). NAEYC Standards for Early Childhood Professional Preparation Programs. Washington, DC: Author. Retrieved March 26, 2015 from: https://www.naeyc.org/files/naeyc/file/positions/ProfPrepStandards09.pdf

NAEYC. (2009). Developmentally appropriate practice in early childhood programs serving children from birth through age 8. Position statement. Washington, DC: Author. Retrieved March 26, 2015 from: http://www.naeyc.org/files/naeyc/file/positions/PSDAP.pdf

National Council for Accreditation of Teacher Education (NCATE). 2012. What makes a teacher effective? Retrieved March 26, 2015 from: http://www.ncate.org/LinkClick.aspx?fileticket=JFRrmWqa1jU\%3d\&tabid=361

Osisioma, I.U., \& Moscovici, E.H. (2008). Profiling the beliefs of the forgotten teachers: An analysis of intern teachers' frameworks for urban science teaching. Journal of Science Teacher Education, 19, 285-311. https://doi.org/10.1007/s10972-008-9093-8

Rhodes, H., \& Huston, A. (2012). Building the workforce our youngest children deserve. Social Policy Report, 26(1). Society for Research in Child Development. Retrieved on July 9, 2016 from: https://files.eric.ed.gov/fulltext/ED531540.pdf

Ryan, S., \& Gibson, M. (2016). Preservice early childhood teacher education. In L. J. Couse \& S. L. Recchia (Eds.), Handbook of Early Childhood Teacher Education (pp. 195-308). New York, NY: Routledge.

Snow, C. E., \& Van Hemel, S. B. (2008). Early childhood assessment: Why, what, and how. Washington, DC: National Academies Press. https://doi.org/10.17226/12446.

Sinatra, R., Zygouris-Coe, V., \& Dasinger, S. (2011). Preventing a vocabulary lag: What lessons are learned from research. Reading \& Writing Quarterly, 28(4), 333-357. https://doi.org/10.1080/10573569.2012.702040

Whitebook, M. (2014) Building a skilled teacher workforce. Berkeley, CA: Center for the Study of Child Care Employment, University of California, Berkeley. Retrieve on July 9, 2015 from: https://earlysuccess.org/sites/default/files/website_files/Gates\%20Fdn-Building\%20a\%20Skilled\%20Teach er\%20Workforce_September\%202014.pdf

Zaslow, M., Tout, K., Halle, T., Whittaker, J. V., \& Lavelle, B. (2010). Toward the identification of features of effective professional development for early childhood educators. Literature Review. Office of Planning, Evaluation and Policy Development, US Department of Education. Retrieved on November 21, 2015 from: https://files.eric.ed.gov/fulltext/ED527140.pdf

\section{Appendix}

Appendix A: Teacher candidate questionnaire

A. Experience

1. What year did you begin graduate coursework in early childhood education at Hunter College?

2. How long have you been teaching in your current grade level?

3. What grade level are you currently teaching?

4. Have you taught any other grade level(s)? $\square$ yes $\square$ no

If yes, what grade level(s)?

5. Do you currently have certification in an area other than early childhood? $\square$ yes $\square$ no If yes, what area?

6. Have you taken any certification exams? $\square$ yes $\square$ no 
If yes, which exams?

$\square$ Educating All Students Test (EAS)

$\square$ Academic Literacy Skills Test (ALST)

Content Specialty Test (CST)

B. Expectations

How familiar are you with the following regarding the requirements of the EdTPA:

\begin{tabular}{|c|c|c|c|c|}
\hline & & Not Familiar & Somewhat Familiar & Very Familiar \\
\hline a. & Planning & (1) & (2) & (3) \\
\hline b. & Instruction & (1) & (2) & (3) \\
\hline c. & Assessment & (1) & (2) & (3) \\
\hline d. & Reflection & (1) & (2) & (3) \\
\hline e. & Analyzing Teaching & (1) & (2) & (3) \\
\hline f. & Language Development & (1) & (2) & (3) \\
\hline g. & Video Submission & (1) & (2) & (3) \\
\hline h. & Artifacts Submission & (1) & (2) & (3) \\
\hline
\end{tabular}

Which area(s) do you feel you need support in regarding the following:

\begin{tabular}{|c|c|c|c|c|}
\hline & & No Support & Some Support & Maximum Support \\
\hline a. & Planning & (1) & (2) & (3) \\
\hline b. & Instruction & (1) & (2) & (3) \\
\hline c. & Assessment & (1) & (2) & (3) \\
\hline d. & Reflection & (1) & (2) & (3) \\
\hline e. & Analyzing Teaching & (1) & (2) & (3) \\
\hline f. & Language Development & (1) & (2) & (3) \\
\hline g. & Video Submission & (1) & (2) & (3) \\
\hline h. & Artifacts and Documentation & (1) & (2) & (3) \\
\hline i. & Other: & & & \\
\hline
\end{tabular}

C. Preparation

Which area(s) do you feel Hunter College early childhood education coursework supported your preparation for the following:

\begin{tabular}{llccc}
\hline & & No Support & Some Support & Maximum Support \\
\hline a. & Planning & $(1)$ & $(2)$ & $(3)$ \\
b. Instruction & $(1)$ & $(2)$ & $(3)$ \\
c. Assessment & $(1)$ & $(2)$ & $(3)$ \\
d. Reflection & $(1)$ & $(2)$ & $(3)$ \\
e. Analyzing Teaching & $(1)$ & $(2)$ & $(3)$ \\
f. Language Development & $(1)$ & $(2)$ & $(3)$ \\
g. Documentation & (1) & $(2)$ & (3) \\
h. Collecting Artifacts & (1) & (2) & (3) \\
i. Other: & & & \\
\hline
\end{tabular}

Which Hunter College early childhood course(s) have supported your preparation for the certification exams:

\begin{tabular}{|c|c|c|c|c|}
\hline & & No Support & Some Support & Maximum Support \\
\hline a. & ECC 703 (Curriculum) & (1) & (2) & (3) \\
\hline b. & ECC 705 (Language and Literacy: B-Kindergarten) & (1) & (2) & (3) \\
\hline c. & ECC 706 (Language and Literacy: Kindergarten- $2^{\text {nd }}$ ) & (1) & (2) & (3) \\
\hline d. & ECC 707 (Language and Literacy: ELL) & (1) & (2) & (3) \\
\hline e. & ECC 708 (Children with Special Needs: Birth-2 ${ }^{\text {nd }}$ ) & (1) & (2) & (3) \\
\hline f. & ECC 710 (Early Childhood Mathematics: Birth- $2^{\text {nd }}$ ) & (1) & (2) & (3) \\
\hline g. & ECC 711 (Science in Early Childhood: Birth-2 ${ }^{\text {nd }}$ ) & (1) & (2) & (3) \\
\hline h. & ECC 713 (The Expressive Arts in Early Childhood) & (1) & (2) & (3) \\
\hline i. & Other: & & & \\
\hline
\end{tabular}


Which course(s) supported you in the following areas (check all that apply):

\begin{tabular}{|c|c|c|c|c|c|c|}
\hline \multirow{2}{*}{ ECC 703} & Planning & Instruction & Assessment & Reflection & Analysis & Language Development \\
\hline & & & & & & \\
\hline ECC 705 & & & & & & \\
\hline ECC 706 & & & & & & \\
\hline ECC 707 & & & & & & \\
\hline ECC 708 & & & & & & \\
\hline ECC 710 & & & & & & \\
\hline ECC 711 & & & & & & \\
\hline ECC 713 & & & & & & \\
\hline Other: & & & & & & \\
\hline
\end{tabular}

Additional Comments:

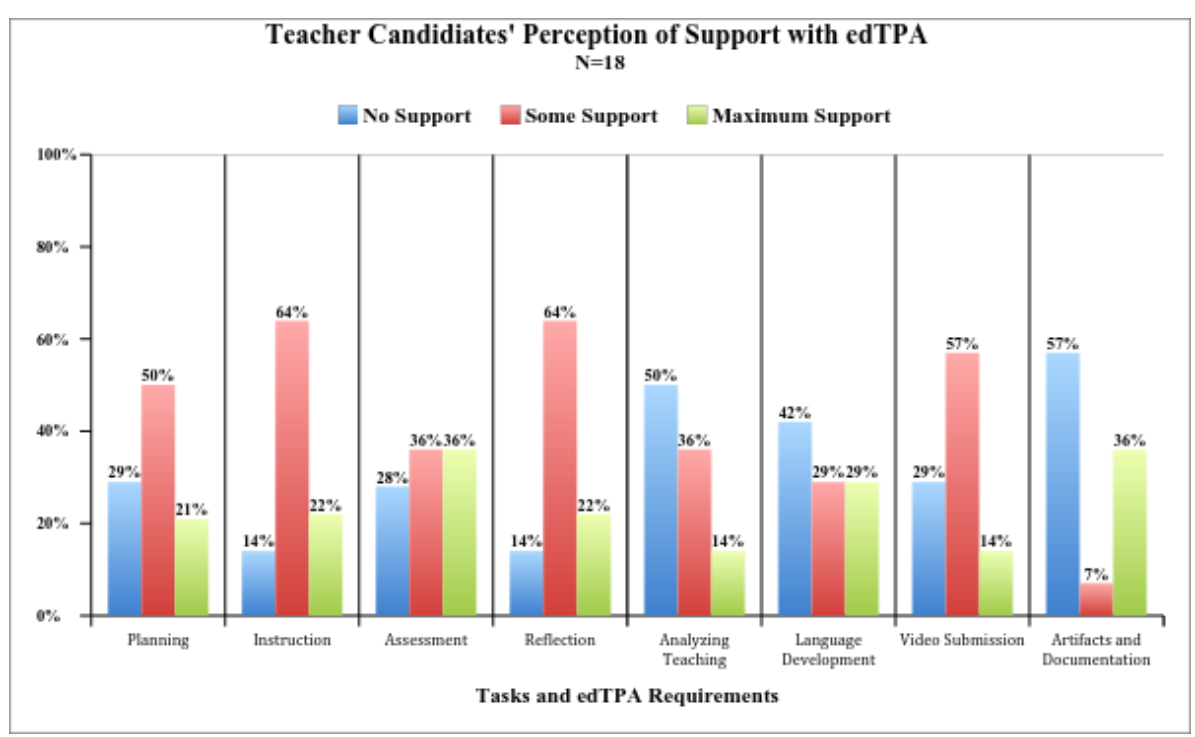

Chart 1. Teacher Candidates' Perception of Support with edTPA

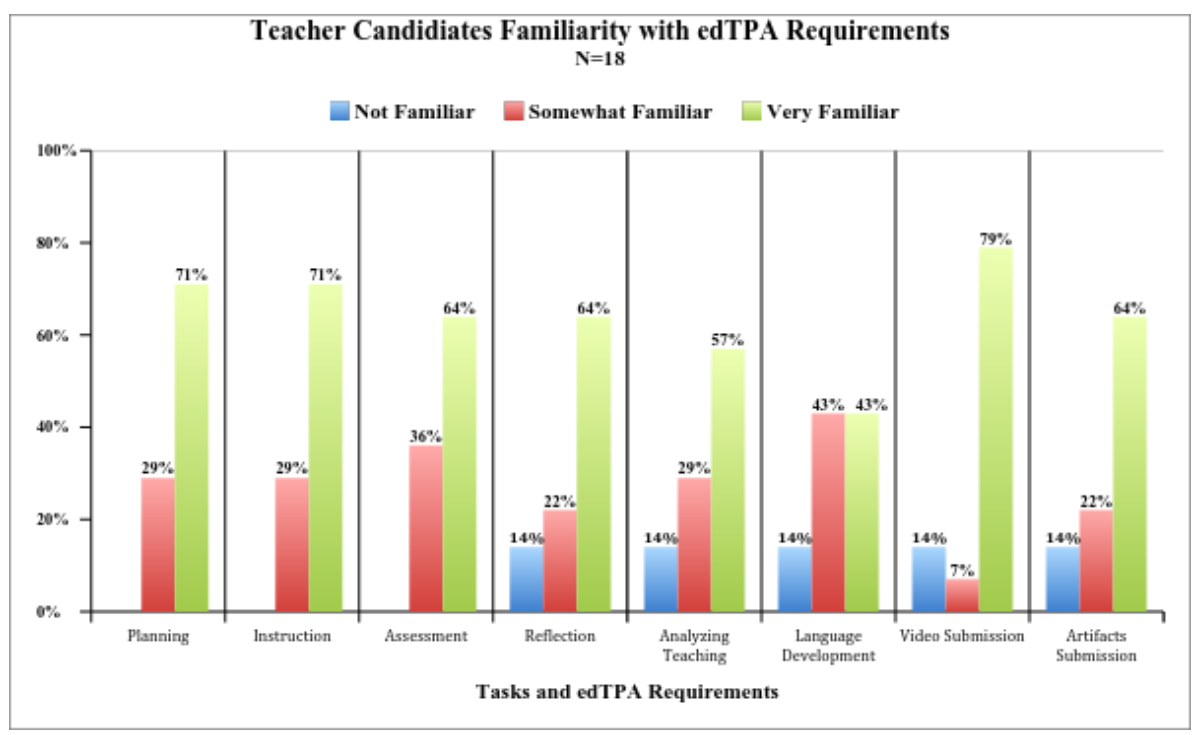

Chart 2. Teacher Candidates' Familiarity 


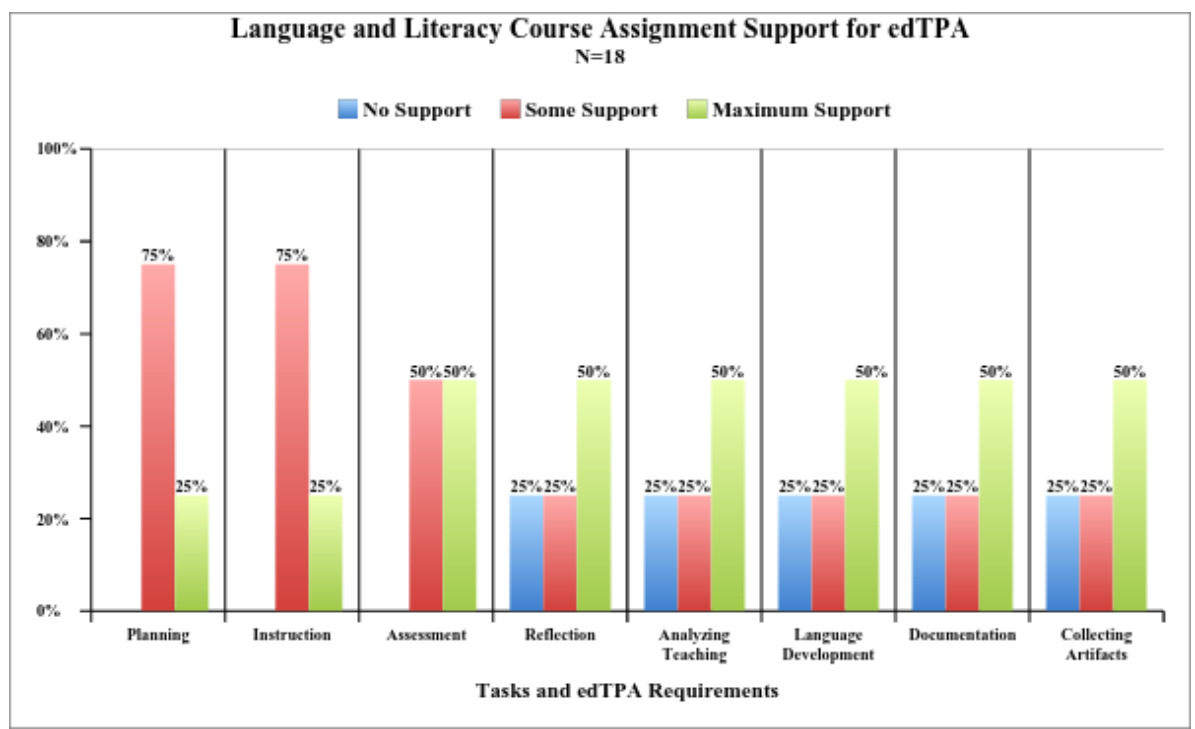

Chart 3. Language and Literacy Support for edTPA

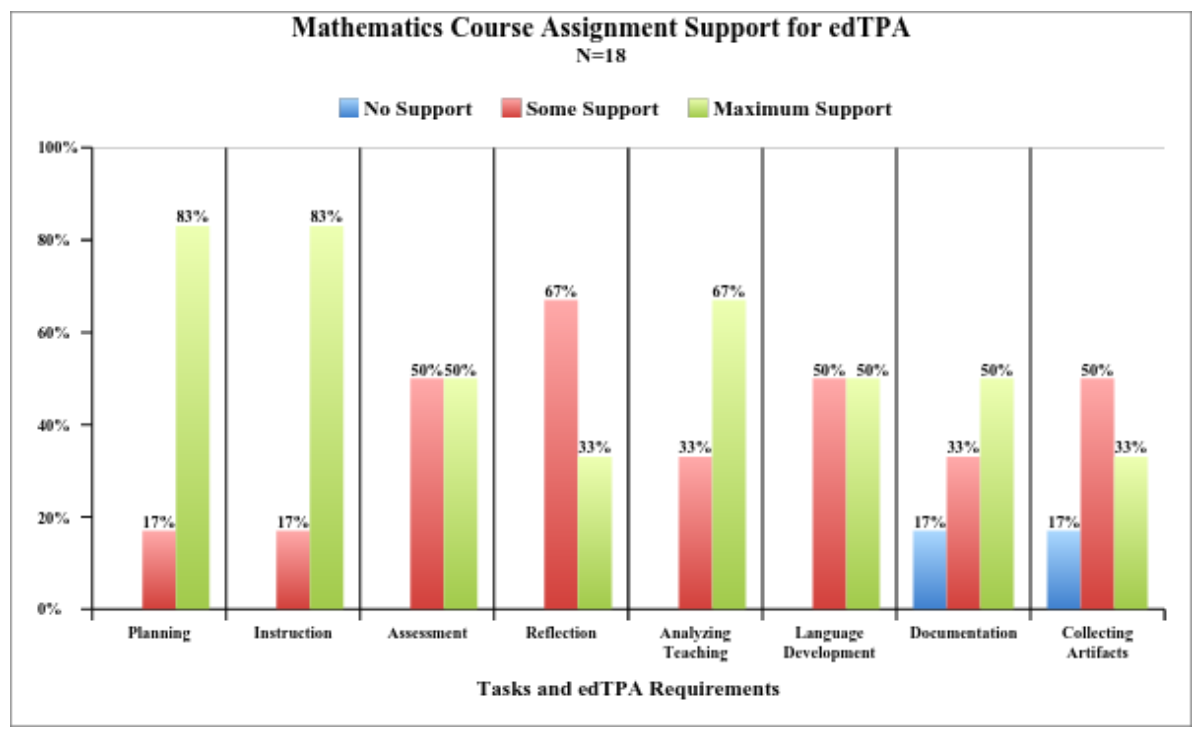

Chart 4. Mathematics Support for edTPA

\section{Copyrights}

Copyright for this article is retained by the author(s), with first publication rights granted to the journal.

This is an open-access article distributed under the terms and conditions of the Creative Commons Attribution license (http://creativecommons.org/licenses/by/4.0/). 